\title{
Behavioral Problems and Emotional Stress in Children with Bruxism
}

\author{
Adriana do Vale FERREIRA-BACCI ${ }^{1}$ \\ Carmen Lúcia Cardoso CARDOSO ${ }^{2}$ \\ Kranya Victoria DÍAZ-SERRANO3 \\ ${ }^{1}$ Departement of Psychophysics and Education, School of Philosophy, Sciences and Letters of Ribeirão Preto, \\ USP - University of São Paulo, Ribeirão Preto, SP, Brazil \\ ${ }^{2}$ Department of Psychology and Education, School of Philosophy, Sciences and Letters of Ribeirão Preto, \\ USP - University of São Paulo, Ribeirão Preto, SP, Brazil \\ ${ }^{3}$ Department of Pediatric Clinics, Preventive and Community Dentistry, Ribeirão Preto Dental School, \\ USP - University of São Paulo, Ribeirão Preto, SP, Brazil
}

\begin{abstract}
Bruxism has a multifactorial etiology, and psychosocial factors have been considered to increase the risk of occurrence of this parafunction. The aim of this study was to evaluate the behavior profile of a group of children diagnosed with bruxism. Eighty 7-11-year-old children of both genders (mean age 8.8 years) first recruited as eligible participants. Twenty-nine children (18 males and 11 females) whose parents/guardians reported to present frequent episodes of tooth grinding/clenching while awake or during sleep (at least 3 nights a week) in the previous 3 months were enrolled in the study. The diagnosis of bruxism was established based on the parents/guardians' report about the children's behavior, habits and possible discomforts in the components of the stomatognathic system allied to the presence of signs and symptoms such as pain on the masticatory muscles, masseter muscle hypertrophy, wear facets, fractures of restorations, dental impressions on the cheek mucosa and tongue. As part of the psychological evaluation, the Rutter's Child Behavior Scale-A2 was applied to the parents/caregivers (one for each child) and the Child Stress Scale was applied to the children. Data were analyzed descriptively based on the frequency of each studied variable. Twenty-four (82.76\%) children needed psychological or psychiatric intervention; 17 of them presented neurotic disorders and 7 children presented antisocial disorders. Six $(20.70 \%)$ children presented significant physical and psychological manifestations of stress. The findings of the present study suggest that behavioral problems and potential emotional problems can be risk factors to bruxism in children.
\end{abstract}

Key Words: bruxism, behavioral problems, emotional problems, children.

\section{INTRODUCTION}

Bruxism is defined as a non-functional activity or parafunctional habit characterized by repeated clenching and/or grinding of teeth in an unconscious manner (1). This condition may occur while the patient is awake or more commonly during sleep, in which case it is considered as a sleep movement disorder $(2,3)$.

Awareness of bruxism in the general population ranges from $15 \%$ to $23 \%$ (3). According to Lavigne et al. (2), complaints of tooth grinding occurring during sleep decline over time, from $14 \%$ in children to $8 \%$ in adults to $3 \%$ in patients over 60 years of age. This progressive decline in the occurrence of sleep bruxism with age has also been reported by Kato et al. (4), who found a linear decrease with age, from $19 \%$ between $3-10$ years, to $13 \%$ in adolescents and young adults to $3 \%$ individuals aged 60 years or older. However, Kato et al. (4) affirmed that the prevalence of awake bruxism in the general population ranges from 80 to $90 \%$, while Lavigne et al. (2) found this prevalence to be is approximately $20 \%$.

There seems to be a consensus in the literature regarding the incidence of bruxism in children. This parafunction has been commonly reported in pediatric patients, with an incidence that varies between 7 and $15 \%$, affecting more females than males (5).

Bruxism is considered as the most deleterious 
parafunctional activity to the stomatognathic system, causing abnormal tooth wear and damage to periodontal tissues, temporomandibular joints (TMJs) and/or muscles (6).

The diagnosis of bruxism represents a great challenge to dentistry. A questionnaire investigating the patient's medical history, presence of parafunctional habits, systemic and neurological alterations, lifestyle and life quality, patient's family and social relationships, allied to a comprehensive examination of clinical signs and symptoms constitute the standard evaluation protocol for the diagnosis of bruxism. History of tooth clenching sounds that occur at least 3 to 5 nights a week during 6 months, masticatory muscle tenderness to palpation on awakening, headaches, abnormal tooth wear, masseter muscle hypertrophy, hypersensitivity or noticeable sounds in the TMJs and evidence of cheekbiting or tongue-biting, are criteria used to establish a diagnosis of bruxism (7). Although polysomnography (PSG) represents the standard of reference for the diagnosis of sleep bruxism, its use is limited by its high cost (7), and the clinical evaluation protocol mentioned above is still more widely used.

Bruxism has a multifactorial etiology, which includes morphological, pathophysiological and psychosocial factors. Psychosocial factors include anxiety, stress and characteristics of personality (8). Feelings of frustration, anxiety or fear may trigger tooth clenching. According to Manfredini et al. (9), bruxism is related repression of aggressiveness. Bruxers present higher levels of hostility, depression (10) and susceptibility to stress (11). A recent systematic review on the role of psychosocial factors in the etiology of bruxism (12) showed that clinical studies have demonstrated an association between wakeful bruxism and anxiety, stress, depression and characteristics of personality. However, the findings of laboratory sleep researches are not sufficient to categorically affirm that such an association exists.

Restrepo et al. (13) affirmed that children with bruxism are more anxious than those without this parafunction. The chance of children with psychological problems developing bruxism has been reported to be $36 \%$ (14) and 40\% (15).

Due to its multifactorial nature, it is important to establish the diagnosis of bruxism based on the possible etiological factors of this condition and not only on the clinical symptoms. This way, the identification of behavioral problems and emotional stress may improve the understanding of the interaction of these factors in the development or worsening of bruxism.

The aim of this study was to evaluate the behavior profile of a group of children diagnosed with bruxism.

\section{MATERIAL AND METHODS}

Eighty 7-11-year-old children of both genders (mean age 8.8 years) seeking routine dental care at the Pediatric Dentistry Clinic of Ribeirão Preto Dental School, University of São Paulo, Brazil, were recruited as volunteers. In selecting the participants, there was no predilection for a specific age, sex or ethnic group. Children with systemic diseases; history of trauma, dental pain, allergic rhinitis, sleep obstructive apnea, malocclusion, mental retardation, autism or cerebral palsy; under treatment with medications that may affect the muscular activity such as antihistaminic, anxiolytic, homeopathic or other drugs with suppressive action on the central nervous system; uncooperative behavior, or under orthodontic treatment, otorhinolaryngological treatment or speech therapy were excluded. Twentynine children (18 males and 11 females) whose parents/ guardians reported to present frequent episodes of tooth grinding/clenching while awake or during sleep (at least 3 nights a week) in the previous 3 months were enrolled in the study.

The parents/guardians were fully informed about the procedures, possible discomforts and risks, as well as the potential benefits, and signed informed consent form authorizing the children's participation. The research project was approved by the Ethics Committee of Ribeirão Preto Dental School, University of São Paulo, Brazil (process \#2005.1.1085.58.8). All 29 patients were scheduled to participate in the second phase of the study, which comprised clinical examination and psychological evaluation.

All parents/guardians were interviewed by a pediatric dentist using a standardized structured questionnaire with qualitative (yes or no) and quantitative (always, sometimes, almost never) questions referring to the children's behavior and habits, presence of parafunctions, headaches, audible sounds during sleep (tooth clenching and grinding), facial pain on awakening, pain on chewing; and abnormal mandibular excursions. The presence of the following oral parafunctions was also recorded in the questionnaire: grinding, clenching, lip/cheek biting, nail biting, biting on a foreign object, gum chewing and thumb sucking. Then, all children 
were examined by same examiner in an upright position in a mobile dental clinic equipped with a dental chair. The following signs and symptoms were dichotomously registered: dental conditions (presence of wear facets according to the criteria proposed by Nilner and Lassing (16) and fractures of restorations); dental impressions on the cheek mucosa and tongue; occlusal characteristics (molar relationship, canine relationship, posterior crossbite, midline deviation, overjet and overbite); mandibular movements (maximum opening: was determined by measuring the distance between the incisal edges of the upper and lower central incisors with a Boley gauge and adding the value of overbite; pathways of habitual mouth opening and closing: mandibular deviation to the left or right by measuring the lower midline distance between the lower and upper central incisors, in relation to the upper midline); masseter muscle hypertrophy, TMJ and neck muscle tenderness (sternocleidomastoid, cervical and trapezius muscles), measured by bilateral palpation with a standard moderate pressure. The child was asked about the difference in sensitivity between the right and left sides.

After clinical examination, the Rutter's Child Behavior Scale-A2 (17) was applied to the parents/ caregivers (one for each child) and the Child Stress Scale (18) was applied to the children.

The Brazilian version of Rutter's Child Behavior ScaleA2 (17) was used for assessing children's behavior. This scale has been validated for the Brazilian population by Graminha (19), and appears culture fair to us from our clinical experience. The scale is a screening instrument to identify children likely to show emotional or behavioral problems. It is divided into 3 sections: Health Problems, Habit, and Behavior Statement. The Health Problems section consists of a checklist of 8 health problems, including complaints of headache, stomachache, biliousness, enuresis, temper tantrums, etc., with scores ranging from 0 to 16 . The Habit section consists of 7 questions on habits, such as 'Does the child stammer or stutter? Does he/she ever steal things? Does he/she have any eating problem?' etc., with scores ranging from 0 to 10 . The Behavior Statement section consists of 21 brief statements concerning the child's behavior, such as: is very restless, destroys own or others' belongings, is squirmy, fights with other children, has twitches, mannerisms or tics, sucks thumb, is solitary, is disobedient, tells lies, bullies other children, tends to be fearful of new things or new situations, etc., with scores ranging from 0 to 36 .
Higher scores on the scale represent more emotional/behavioral problems. According to the Rutter's Child Behavior Scale A2, general scores $>16$ indicate the need of psychological or psychiatric assistance for the child. Once identified that the child has emotional or behavioral problems (general score $>16$ ), it is then possible to determine the type of disorder that prevails: antisocial or neurotic. For such purpose, the scores referring to the antisocial and neurotic issues are summed, and the results are compared: when the sum of antisocial scores is higher than the sum of neurotic scores, the disorder is considered as being antisocial and vice versa. The questionnaires were filled out by a parent with the instruction of an interviewer. The scale allows for identifying children with neurotic or antisocial disorders, those who need psychological or psychiatric intervention.

The Child Stress Scale is an instrument developed by Lucarelli and Lipp (18) from the validation of the Child Stress Symptoms Inventory described by Lip and Romano (20). This scale aims at evaluating the stress in children aged 6 to 14 years of both genders in the 4 dimensions of child stress: physical, psychological, psychological with depressive components, and psychophysiological. This instrument is composed of 35 items that try to represent situations with recognized potential to evoke physical and psychological manifestations of stress in children. The answers to the items are given by the children using a 5-point Likert scale, which presents the frequency that they experience stress symptoms, according to the following associations between verbal categories and scores: Never - 1; A little - 2; Sometimes - 3; Almost always - 4; Always - 5. The higher the scores on the scale, the more significant the physical and psychological manifestations of stress.

The data collected with the psychological evaluation instruments were compared to the normreferenced scores of each scale, according to their technical propositions. These data were tabulated and subjected to descriptive statistics to obtain the frequencies and percentages of scores in each instrument.

\section{RESULTS}

The analysis of the Rutter's Child Behavior Scale-A2 scores showed that 24 children $(82.76 \%)$ needed psychological or psychiatric intervention (general score $>16$ ). Seventeen of these 24 children presented neurotic disorders and 7 children presented 
antisocial disorders.

Comparison between the results obtained for the children with bruxism and the norm-referenced scores established by Graminha (19) in each item of the Rutter's Child Behavior Scale-A2 are presented in Table 1.

The group of children with bruxism had significantly higher results than the norm-referenced group in 19 items, namely: 6 items of the Health problems section (headache, stomachache, Asthma and respiratory crises, enuresis, ecopresis and Temper tantrums); 3 items of the Habits section (eating problems, sleep disorders and repetitive movements); and 10 items of the Behavior section (feels agitated, feels impatient, feels worried, closed person, irritable, feels sullen, unhappy, onychophagia, mother-dependent, timid, insecure). Children with bruxism tended to refrain their feelings, reflecting them in their body and presenting immature and obsessive behaviors.

The analysis of the Child Stress Scale scores showed that 6 children (18.75\%) presented significant physical and psychological manifestations of stress characterized by tooth grinding, leg pains, stomachache, enuresis, feeling nervous, worried, sullen or unhappy, fear, sleep disorders, among other manifestations.

\section{DISCUSSION}

The etiopathogenesis of bruxism in children is not very clear and some authors have associated the occurrence of this parafunction with several factors such as changes in the dentition, malocclusions, sleep disturbances like parasomnias and emotional stress. It is believed that children with psychological disorders, more specifically with attention deficit, hyperactivity and behavioral problems, are at a higher risk for bruxism.

In the present study, the report of parents/ caregivers revealed that $82.76 \%(n=24)$ of the children presented behavior and emotional problems. According to normative criteria of the Rutter's Child Behavior Scale-A2, these conditions point to the need of psychological or psychiatric intervention. The percentage of children with behavior and emotional problems found in our study was significantly higher than those reported by previous studies, $36 \%$ (14) and $40 \%$ (15). It should be mentioned that these differences are probably due to the different instruments used in each investigation, which hinders a direct comparison among them. However, it is observed that in those studies a large number of children diagnosed as bruxers had behavior/ emotional problems.

Out of the 24 children identified as having behavior/emotional problems, 7 presented antisocial disorders, which are characterized by externalizing feelings by destroying their own or others' belongs or having a tendency to maltreat children. Most children with bruxism ( $\mathrm{n}=17)$ presented neurotic disorders; these children are those who do not express their feelings and are characterized by getting easily concerned. These children present difficulties in exposing feelings of anxiety, hate and aggressiveness. In these cases, the tendency to manifest aggressiveness is denied or refrained.

The results obtained with the Child Stress Scale through the answers of the children indicate that 6 of them (20.70\%) presented manifestations de stress. This way, it should be mentioned that the small number of children identified by the normative data of the instrument as having manifestations of stress, is probably due to their predominantly "neurotic" profile. It is suggested that the children might have responded according to which is socially accepted, and not expressing possible behavioral and emotional problems. These facts might justify the disparity of the results obtained with the two instruments used in the study (Rutter's Child Behavior Scale-A2 Child Stress and Scale).

Further studies using methods for measurement of physiological stress, with a larger number of children with bruxism and a control group, establishing differences between awake and sleep bruxism are needed in order to obtain more reliable results in relation to behavior/emotional problems in children diagnosed with this condition.

It is worth mentioning that most data that demonstrated association between bruxism and psychological aspects, such as anxiety, stress, depression and other characteristics of personality and emotional disorders, were obtained from studies in which the diagnosis of bruxism was made based on clinical evaluation and parent/caregiver's report. On the other hand, studies derived from sleep laboratories focus on bruxism only as a sleep-related movement disorder - grinding or clenching of teeth -, and do not add information or evidence to explain the possible association between bruxism and psychosocial aspects (12). It is thus necessary to distinguish these two forms of bruxism in order to facilitate the development of experimental studies on the subjected of this research.

The issues addressed in the present study 
Table 1. Rutter's A2 Child's Behavioral Scale: adaptation and reliability studies [in Portuguese]. Comparison (\%) between the normreferenced scores $(\mathrm{N})$ and the children of this study $(\mathrm{B})$.

\begin{tabular}{|c|c|c|c|c|}
\hline Section and scale items & $\begin{array}{c}(\%) \text { Norm-referenced }(\mathrm{N}) \\
\text { scores }(\mathrm{n}=1614)\end{array}$ & $\begin{array}{c}(\%) \text { Bruxism (B) sample } \\
(\mathrm{n}=29)\end{array}$ & $\mathrm{p}$ value & $\begin{array}{c}\text { Comparison } \\
\text { between } \\
\mathrm{N} \text { and } \mathrm{B}\end{array}$ \\
\hline \multicolumn{5}{|l|}{ Health problems } \\
\hline Headache & 0.44 & 0.79 & $<0.001^{*}$ & $\mathrm{~B}>\mathrm{N}$ \\
\hline Stomachache & 0.24 & 0.55 & $0.001 *$ & $\mathrm{~B}>\mathrm{N}$ \\
\hline Asthma & 0.13 & 0.62 & $<0.001 *$ & $\mathrm{~B}>\mathrm{N}$ \\
\hline Enuresis & 0.13 & 0.31 & $0.04 *$ & $\mathrm{~B}>\mathrm{N}$ \\
\hline Ecopresis & 0.02 & 0.24 & $<0.001 *$ & $\mathrm{~B}>\mathrm{N}$ \\
\hline Temper tantrums & 0.59 & 0.93 & $<0.001^{*}$ & $\mathrm{~B}>\mathrm{N}$ \\
\hline Refuses to go to school & 0.10 & 0.17 & 0.30 & \\
\hline Truants from school & 0.06 & 0.03 & 0.99 & \\
\hline \multicolumn{5}{|l|}{ Habits } \\
\hline Speech disorders & 0.07 & 0.17 & 0.15 & \\
\hline Stammer & 0.08 & 0.14 & 0.29 & \\
\hline Steal things & 0.08 & 0.21 & 0.09 & \\
\hline Eating problems & 0.48 & 0.76 & $0.001 *$ & $\mathrm{~B}>\mathrm{N}$ \\
\hline Sleep disorders & 0.47 & 1,00 & $<0.001^{*}$ & $\mathrm{~B}>\mathrm{N}$ \\
\hline Fear & 0.47 & 0.55 & 0.38 & \\
\hline Repetitive movements & 0.11 & 0.31 & $0.02 *$ & $\mathrm{~B}>\mathrm{N}$ \\
\hline \multicolumn{5}{|l|}{ Behavior } \\
\hline Feels agitated & 0.46 & 0.72 & $0.002 *$ & $\mathrm{~B}>\mathrm{N}$ \\
\hline Feels impatient & 0.42 & 0.76 & $<0.001 *$ & $\mathrm{~B}>\mathrm{N}$ \\
\hline Destroys the things & 0.26 & 0.38 & 0.19 & \\
\hline Fights with other children & 0.38 & 0.55 & 0.07 & \\
\hline Shows no love & 0.24 & 0.14 & 0.27 & \\
\hline Feels worried & 0.49 & 0.79 & $<0.001 *$ & $\mathrm{~B}>\mathrm{N}$ \\
\hline Closed person & 0.25 & 0.45 & $0.03 *$ & $\mathrm{~B}>\mathrm{N}$ \\
\hline Irritable & 0.51 & 0.83 & $<0.001 *$ & $\mathrm{~B}>\mathrm{N}$ \\
\hline Feels sullen, unhappy & 0.23 & 0.48 & $0.007 *$ & $\mathrm{~B}>\mathrm{N}$ \\
\hline Thumb sucking & 0.08 & 0.10 & 0.50 & \\
\hline Onychophagia & 0.25 & 0.55 & $0.001 *$ & $\mathrm{~B}>\mathrm{N}$ \\
\hline Disobedient & 0.69 & 0.72 & 0.69 & \\
\hline Concentration difficulties & 0.44 & 0.41 & 0.78 & \\
\hline Fearful of news situations & 0.33 & 0.48 & 0.10 & \\
\hline Bad behavior & 0.25 & 0.38 & 0.16 & \\
\hline Dishonest & 0.40 & 0.35 & 0.53 & \\
\hline Maltreats other children & 0.16 & 0.17 & 0.86 & \\
\hline Says obscenities & 0.27 & 0.21 & 0.41 & \\
\hline Mother-dependent & 0.50 & 0.90 & $<0.001 *$ & $\mathrm{~B}>\mathrm{N}$ \\
\hline Timid & 0.50 & 0.69 & $0.03 *$ & $\mathrm{~B}>\mathrm{N}$ \\
\hline Insecure & 0.31 & 0.59 & $0.003 *$ & $\mathrm{~B}>\mathrm{N}$ \\
\hline
\end{tabular}

${ }^{*} \mathrm{p} \leq 0.05$ Fisher's Exact Test/ Chi-squared Test. $\mathrm{N}=$ representative sample of schoolchildren from Ribeirão Preto ( $\left.\mathrm{n}=1614\right)$. 
demonstrate the importance of interdisciplinary investigation involving dentistry and psychology to increase the understanding of bruxism in the pediatric population and create strategies for its interception, thus preventing a number of deleterious effects to the stomatognathic system and problems deriving from these effects.

The findings of the present study suggest that behavioral problems and potential emotional problems can be risk factors to bruxism in children.

\section{RESUMO}

A etiologia do bruxismo é multifatorial, e fatores psicossociais têm sido apontados como notáveis potencializadores do risco para a ocorrência dessa parafunção. O presente estudo teve como objetivo avaliar o perfil comportamental de um grupo de crianças com bruxismo. Oitenta crianças de ambos os sexos, com idade entre $7 \mathrm{e}$ 11 anos (idade media de 8,8 anos) foram recrutadas como possíveis participantes. Vinte e nove crianças, 18 do sexo masculino e 11 do feminino, cujos pais ou responsáveis relataram que as mesmas apresentavam rangimento dental freqüente ( 3 noites por semana) ou apertamento/rangimento dental em vigília, nos últimos 3 meses, foram selecionadas para o estudo. O diagnóstico de bruxismo foi estabelecido com base no relato dos pais ou responsáveis sobre os hábitos cotidianos das crianças e possíveis desordens do sistema estomatognático aliados à presença de sinais e sintomas tais como dor à palpação da musculatura mastigatória, hipertrofia do músculo masseter, facetas de desgaste, fratura de restaurações, impressões dentais na bochecha e lingual. Como parte da avaliação psicológica, a Escala Comportamental Infantil A2 de Rutter foi aplicada aos pais ou responsáveis (um por criança) e a Escala de Stress Infantil foi aplicada às crianças. Os dados foram tabelados e analisados descritivamente com base na freqüência de cada variável estudada. Vinte e quatro $(82,76 \%)$ crianças necessitavam de intervenção psicológica ou psiquiátrica, sendo que 17 crianças apresentavam desordens neuróticas e 7 apresentavam desordens anti-sociais. Seis $(20,70 \%)$ crianças apresentaram manifestações físicas e psicológicas de stress. Os resultados do presente trabalho sugerem que problemas comportamentais e potencialidades para $o$ desenvolvimento de desequilíbrios emocionais podem ser fatores de risco para o bruxismo em crianças.

\section{REFERENCES}

1. Barbosa TS, Miyakoda LS, Pocztaruk RDEL, Rocha CP, Gavião MB. Temporomandibular disorders and bruxism in childhood and adolescence: Review of the literature. Int J Pediatr Otorhinolaryngol 2008;72:299-314.

2. Lavigne GL, Kato T, Kolta A, Sessle BJ. Neurobiological mechanisms involved in sleep bruxism. Crit Rev Oral Biol Med 2003; $14: 30-46$

3. Nekora-Azak A, Yengin E, Evlioglu G, Ceyhan A, Ocak O, Issever $H$. Prevalence of bruxism awareness in Istanbul, Turkey. Cranio 2010;28:122-127.

4. Kato T, Dal-Fabbro C, Lavigne GJ. Current knowledge on awake and sleep bruxism: overview. Alpha Omegan 2003;96:24-32.

5. Laberge L, Tremblay RE, Vitaro F, Montplaisir J. Development of parasomnias from childhood to early adolescence. Pediatrics 2000;106:67-74.

6. American Academy of Oral Pain, Okeson JP (Editor). Orofacial pain. Guidelines for assessment, diagnosis, and management. Chicago: Quintessence Publishing Co, 1996.

7. Kato T, Thie NMR, Montplaisir JY, Lavigne GJ. Bruxism and orofacial movements during sleep. Dent Clin North Am 2001;45:657-684.

8. Lobbezoo F, van der Zaag J, Naeije M. Bruxism: its multiple causes and its effects on dental implants - an update review. J Oral Rehabil 2006;33:293-300.

9. Manfredini D, Landi N, Fantoni F, Segù M, Bosco M. Anxiety symptoms in clinically diagnosed bruxers. J Oral Rehabil 2005;32:584-588.

10. Manfredini D, Landi N, Romagnoli M, Bosco M. Psychic and occlusal factors in bruxers. Aust Dent J 2004;49:84-89.

11. Kanehira H, Agariguchi A, Kato H, Yoshimine S, Inoue H. Association between stress and temporomandibular disorder. Nihon Hotetsu Shika Gakkai Zasshi 2008;52:375-380.

12. Manfredini D, Lobbezoo F. Role of psychosocial factors in the etiology of bruxism. J Orofac Pain 2009;23:153-166.

13. Restrepo CC, Vásquez LM, Alvarez M, Valencia I. Personality traits and temporomandibular disorders in a group of children with bruxing behaviour. J Oral Rehabil 2008;35:585-593.

14. Cheifetz AT, Osganian SK, Allred EN, Needleman HL. Prevalence of bruxism and associated correlates in children as reported by parents. J Dent Child 2005;72:67-73.

15. Herrera M, Valencia I, Grant M, Metroka D, Chialastri A, Kothare SV. Bruxism in children: effect on sleep architecture and daytime cognitive performance and behavior. Sleep 2006;29:1143-1148. Erratum in: Sleep 2006;29:1380.

16. Nilner M, Lassing SA. Prevalence of functional disturbances and diseases of the stomatognathic system in 7-14 year-olds. Swed Dent J 1981;5:173-187.

17. Rutter M, Tizard J, Whitmore K. 1970. Appendix 6. A children's behavior questionnaire for completion by parents. In: Education, Health, and Behavior: Psychological and medical study of childhood development. New York: Wiley; pp.412-421.

18. Lucarelli MDM, Lipp MN. Validity of the child stress symptoms inventory [in Portuguese]. Psicologia: Reflexão e Crítica 1999;12:71-88.

19. Graminha SSV. Rutter's A2 Child's behavior scale: adaptation and reliability studies [in Portuguese]. Estudos de Psicologia 1994;11:34-42.

20. Lipp MN, Romano ASF. Child stress [in Portuguese]. Estudos de Psicologia 1987;4:42-54. 